\title{
Avaliação das comunidades fúngicas encontradas em amostras de solo: uma revisão sistemática da literatura
}

No solo os microrganismos possuem diversas funções, sendo responsáveis por inúmeras reações bioquímicas, não só relacionados com a transformação da matéria-orgânica, mas também com o intemperismo das rochas, desempenhando papel importantíssimo na gênese do solo. Decompõem a matéria-orgânica, realizam a ciclagem de nutrientes e de energia, interferindo no crescimento de plantas. Produzem compostos complexos que agregam o solo, fazem a decomposição de xenobióticos, atuando na biorremediação de poluentes e de agrotóxicos, na formação de associações micorrízicas, na fixação biológica do nitrogênio, no controle de pragas, e, além disso tudo, causam doenças. O conhecimento dos microrganismos do solo é fundamental para o levantamento taxonômico das populações que estão ali, podendo levar ao descobrimento de processos metabólicos utilizados por estes organismos, tornando-se importantes para as o levantamento taxonômico das populações que estão ali, podendo levar ao descobrimento de processos metabólicos utilizados por estes organismos, tornando-se importantes para as
interações ambientais e aplicações biotecnológicas. Assim, o presente trabalho teve como objetivo identificar, por meio de pesquisas já publicadas, a diversidade de fungos presentes em diferentes tipos de solo, avaliando a influência das características do solo sobre as comunidades fúngicas. Os solos analisados variaram de amostras urbanas a solos de áreas nativas, argilosos, arenosos ou orgânicos (compostagem). Quanto aos microrganismos, os gêneros citados com mais frequência nos estudos foram Penicillium spp., seguido de Fusarium spp., Aspergillus spp., Trichoderma spp., e Verticillium spp. Concluiu-se que grande parte dos microrganismos mencionados nos trabalhos já são ou podem ser utilizados para fins biotecnológicos, sendo fontes de diversas enzimas e produtores de compostos importantes. Aspectos generalistas referentes à umidade, à temperatura, à posição e à composição orgânica do solo mostraram influenciar no desenvolvimento dos fungos, nos quais solos mais úmidos, superficiais e como maior oferta de material orgânico aumentam a presença e o crescimento destes indivíduos.

Palavras-chave: Fungos geofílicos; Solo; Biotecnologia.

\section{Evaluation of fungal communities found in soil samples: a systematic review of literature}

\begin{abstract}
In soil microorganisms have several functions, being responsible for numerous biochemical reactions, not only related to the transformation of organic matter, but also to the weathering of rocks, playing a very important role in soil genesis. They break down organic matter, perform nutrient and energy cycling, interfering with plant growth. They produce complex compounds that aggregate the soil, decompose xenobiotics, act in bioremediation of pollutants and pesticides, formation of mycorrhizal associations, biological nitrogen fixation, pest control, and, in addition, cause disease. The knowledge of the microorganisms of the soil is fundamental for the taxonomic survey of the populations that are there, being able to lead to the discovery of the metabolic processes used by these organisms, becoming important for the environmental interactions and biotechnological applications. The present work had as objective to know, through metabolic processes used by these organisms, becoming important for the environmental interactions and biotechnological applications. The present work had as objective to know, through
already published research, the diversity of fungi present in different types of soil, evaluating the influence of the soil characteristics on the fungal communities. The analyzed soils varied already published research, the diversity of fungi present in different types of soil, evaluating the influence of the soil characteristics on the fungal communities. The analyzed soils varied Fusarium spp., Aspergillus spp., Trichoderma spp., and Verticillium spp. It was concluded that most of the microorganisms mentioned in the work are already or can be used for biotechnological purposes, being sources of several enzymes and producers of important compounds. General aspects related to soil moisture, temperature, position and organic composition have influenced the development of fungi, where more humid and superficial soils and a greater supply of organic material increase the presence and growth of these organisms.
\end{abstract}

Keywords: Geophilic fungi; Soil; Biotechnology.

Topic: Microbiologia Agrícola e Ambiental

Reviewed anonymously in the process of blind peer.
Received: 02/10/2019

Approved: $26 / 11 / 2019$
Fabíola Dresch (iD)

Universidade do Vale do Taquari, Brasil http://lattes.cnpq.br/0431010864903078 http://orcid.org/0000-0002-8863-2883

fdresch@universo.univates.br

Daiane Flores Dalla Lana (iD)

Universidade Federal de Ciências da Saúde de Porto Alegre http://lattes.cnpq.br/2477648307638964

http://orcid.org/0000-0003-3612-7305

dayalana@hotmail.com

\section{Mônica Jachetti Maciel (iD)}

Universidade do Vale do Taquari, Brasil

http://lattes.cnpq.br/2575088289818885

http://orcid.org/0000-0002-6863-2181

monicajm@univates.br
Referencing this:

DRESCH, F.; LANA, D. F. D.; MACIEL, M. J.. Avaliação das comunidades fúngicas encontradas em amostras de solo: uma revisão sistemática da literatura. Revista Ibero Americana de Ciências Ambientais, v.10, n.6, p.67-76, 2019. DOI: http://doi.org/10.6008/CBPC21796858.2019.006.0007 


\section{INTRODUÇÃO}

Os fungos são considerados microrganismos de grande importância ecológica e econômica por conta do seu potencial decompositor de matéria e produção de enzimas extracelulares, sendo utilizados em diversas áreas como alimentar, ambiental e médica (SILVA et al., 2006). Possuem uma ampla distribuição na natureza, sendo encontrados em vários habitats, como: ar, água, animais, alimentos e solos.

Seguido das bactérias, centenas e milhares de diferentes espécies fúngicas, com exceção das leveduras, habitam o solo. Neste local estão situados mais próximos da superfície, pois as condições de aerobiose são abundantes. As características químicas e físicas do solo influenciam no tipo de fungo predominante. As principais espécies encontradas são: Penicillium, Mucor, Cladosporium, Fusarium, Aspergillus, Rhizopus e Trichoderma (CARDOSO et al., 2016; CARVALHO, 2008). Os fungos são ótimos decompositores de matéria-orgânica de tecidos de plantas, como celulose e lignina. Ao contrário dos demais fungos, as leveduras são encontradas em menor quantidade e frequentemente em solos de vinhedos, pomares e apiários, visto que, estão presentes nas folhas e frutas que caem no solo (CARDOSO et al., 2016).

No solo, os fungos são encontrados em grandes quantidades, variando de $10^{4}$ a $10^{6}$ por grama, participando ativamente dos processos de biodeterioração e biodegradação decompondo a matériaorgânica por meio da degradação de dejetos e restos mortais de animais e tecidos de plantas, transformandoos em substâncias capazes de enriquecer o solo. Além disso, atuam também na decomposição de xenobióticos, fazem o controle biológico, estabelecem relações simbióticas e promovem a agregação do solo e a mineralização de nutrientes (CAVALCANTI et al., 2006; CARDOSO et al., 2016). Assim, por conta do seu potencial decompositor de matéria e produção de enzimas extracelulares, os fungos possuem importância ecológica e econômica sendo utilizados em diversas áreas como de alimentos, ambiental e médica (SILVA et al., 2006). Muitos pesquisadores têm aproveitado a diversidade e isolado microrganismos dos mais diversos ambientes para a produção de bioprodutos, pois o ambiente de onde são isolados, relaciona-se com os materiais dos quais esses indivíduos são capazes de degradar.

Diversos estudos mostram que o uso da terra e o tipo de solo determinam a composição bacteriana. Porém, existem poucos estudos em relação a esses efeitos sobre a comunidade de fungos (CARSON et al., 2010). Algumas pesquisas relatam que as mudanças de uso de terras e os tipos de solo podem afetar a estrutura das comunidades de fungos de diferentes maneiras, por isso as populações variam dependendo do tipo do solo, da vegetação e das condições climáticas (MOREIRA et al., 2006).

Assim, percebe-se que o conhecimento dos microrganismos do solo é fundamental para o levantamento taxonômico das populações que estão ali, podendo levar ao descobrimento de processos metabólicos utilizados por estes organismos, tornando-se importantes para as interações ambientais e aplicações biotecnológicas. Diante disso, o presente trabalho tem como objetivo identificar, por meio de pesquisas já publicadas, a diversidade de fungos microscópicos presentes em diferentes tipos de solo, avaliando a influência das características do solo sobre as comunidades fúngicas. 


\section{METODOLOGIA}

O presente trabalho realizou uma revisão sistemática da literatura de natureza descritiva com abordagem qualitativa e quantitativa, baseando-se na pesquisa com a combinação dos descritores: 'fungos filamentosos' AND 'solo' AND 'biota' e com os seus equivalentes em inglês e espanhol. A pesquisa foi feita nas bases de dados indexadas Scientific Electronic Library Online (ScIELO) e Literatura Latino-Americana e do Caribe em Ciências da Saúde (LILACS). Não foram utilizados limites de datas de publicação, pois se trata de um assunto pouco abordado na literatura.

Os artigos foram armazenados em disco rígido (Hard Disk), separados em duas pastas, nomeadas: SciELO e LILACS. Dentro dessas pastas, os artigos encontrados na busca foram distribuídos em subpastas, nomeadas com o nome dos autores e ano de publicação. Para o acesso ao texto completo, foi acessado o link disponível diretamente na própria base de dados selecionada. A busca pelas produções resultou inicialmente nos seguintes números nas referidas bases de dados: 282 artigos/produções científicas na LILACS e 2 na SCIELO, totalizando 284 produções. Por fim, a partir do estabelecimento dos critérios de inclusão e exclusão, esta revisão se constituiu de 10 artigos oriundos da base de dados LILACS.

A análise dos artigos encontrados foi realizada em três etapas. Inicialmente foram lidos todos os títulos dos artigos encontrados nas bases de dados com os descritores utilizados, sendo selecionados os que apresentaram termos relacionados com presença de fungos no solo. Depois de selecionados os artigos, partiu-se para a segunda etapa, que se constituiu na leitura dos resumos. Foram selecionados para a terceira etapa os artigos que contemplavam os critérios de inclusão, ou seja, que mencionavam alguma informação quanto a identificação da espécie e/ou gênero de fungos encontrados em amostras de solo. Por fim, na terceira e última etapa do estudo, foram lidos e avaliados os textos integrais dos artigos selecionados na segunda etapa, a fim de explorar as informações dos estudos e concluir os objetivos desta revisão, sendo essa análise qualitativa, onde se extraiu os principais dados dos artigos escolhidos, o quais foram apresentados em forma de tabela.

O critério de inclusão utilizado para a seleção dos artigos analisados baseou-se nas informações que continham a identificação da espécie e/ou gênero de fungos encontrados nas diferentes amostras de solo analisadas. Durante a seleção, foram excluídos trabalhos cujas amostras não eram de solo, pesquisas que envolviam apenas fungos micorrízicos, trabalhos que não diferenciavam a identificação dos fungos encontrados, artigos duplos ou repetidos entre as bases de dados, além daqueles publicados sob a forma de editoriais, entrevistas, projetos, notas clínicas e revisões. Sendo utilizados neste trabalho apenas artigos científicos. Destaca-se que foram contabilizados apenas uma vez os artigos repetidos nas bases de dados.

\section{RESULTADOS}

A busca nas bases de dados selecionou, no total, 284 artigos que contemplavam os descritores utilizados na pesquisa. Desses, após aplicados os critérios de inclusão e de exclusão, 10 foram selecionados e incluídos nesta revisão (Figura 1), os quais continham as informações necessárias para desenvolvimento da 
análise de resultados.

Embora na primeira busca tenha sido encontrado diversos estudos, a grande maioria deles não diferenciavam a comunidade fúngica analisada, ou às vezes informavam somente a classe ou família dos fungos, ou continham apenas informações a respeito do desenvolvimento dos microrganismos. Além disso, muitos estudos eram feitos com base em análise de fungos micorrizas.

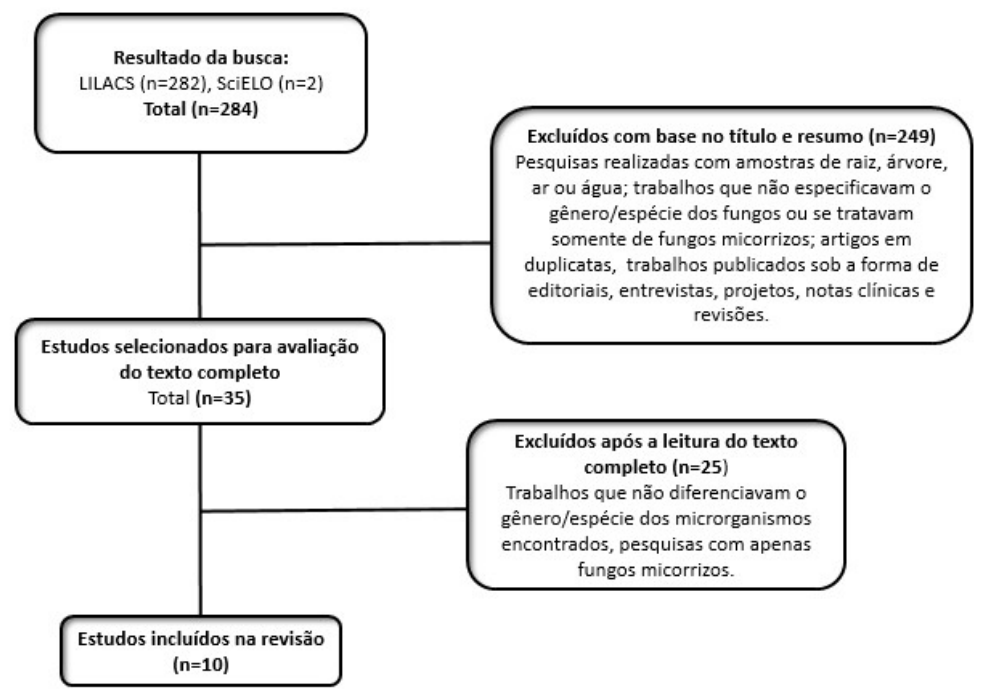

Figura 1: Fluxograma dos artigos selecionados para a revisão.

Tabela 1: Autores e principais resultados dos artigos utilizados na revisão que analisaram a presença de fungos em amostras de solo.

\begin{tabular}{|c|c|c|}
\hline Referências & Tipos de solos analisados & Principais fungos encontrados \\
\hline HAAS et al. (2016) & $\begin{array}{l}\text { Solos de plantas comerciais, compostos de } \\
\text { jardim (compostagem), solos superficiais e } \\
\text { sub-superficiais de plantas em vaso }\end{array}$ & $\begin{array}{l}\text { Penicillium spp., Aspergillus spp., Mucor spp., Fusarium spp., } e \\
\text { Cladosporium spp. } e \text { Trichoderma spp. }\end{array}$ \\
\hline $\begin{array}{l}\text { ESTRADA-MEDINA et } \\
\text { al. (2016) }\end{array}$ & $\begin{array}{l}\text { Dois tipos de solos (planícies e montes) do } \\
\text { estado de Yucatán (México) }\end{array}$ & $\begin{array}{l}\text { Fusarium sp., Chaetomella raphigera, Humicola sp., Cochliobolus sp., } \\
\text { Zopfiella sp., Stagonosporopsis cucurbitacearum, Periconia } \\
\text { macrospinosa, Verticillium sp., Madurella sp. e Malassezia sp. }\end{array}$ \\
\hline $\begin{array}{l}\text { SARMIENTO et al. } \\
(2016)\end{array}$ & $\begin{array}{l}\text { Solos de dois parques públicos na Argentina, } \\
\text { situados em áreas urbanas (Argentina) }\end{array}$ & $\begin{array}{l}\text { Penicillium pinophilum, Fusarium oxysporum, Aspergillus spp., } \\
\text { Alternaria sp., Microsporum canis, Chrysosporium indicum, } \\
\text { Chrysosporium keratinophilum, Purpureocillium lilacinum, Verticillium } \\
\text { sp., Curvularia clavata, }\end{array}$ \\
\hline $\begin{array}{l}\text { LANGARICA-FUENTES } \\
\text { et al. (2015) }\end{array}$ & $\begin{array}{l}\text { Solos de sistemas domésticos de } \\
\text { compostagem (Inglaterra) }\end{array}$ & $\begin{array}{l}\text { Aspergillus fumigatus, Malbranchea cinnamomea, Thermomyces } \\
\text { lanuginosus, Myceliophthora thermophila, Chaetomium sp., Emericella } \\
\text { nidulans, Thielavia terrestris, Penicillium spp., Mortierella sp., } e \\
\text { Fusarium spp. }\end{array}$ \\
\hline YU et al. (2013) & $\begin{array}{l}\text { Amostras de solo sob copas de plantas e } \\
\text { árvores (Israel) }\end{array}$ & $\begin{array}{l}\text { Penicillium simplicissium, Fusarium oxysporum, Microascus } \\
\text { trigonosporus, Aspergillus niveus, Penicillium chrysogenum, } \\
\text { Actinomucor elegans, Alternaria chlamydospora, Cladosporium } \\
\text { cladosporioides e Ultrumadio atrum. }\end{array}$ \\
\hline HU et al. (2014) & $\begin{array}{l}\text { Amostras de solo com adição de biochar } \\
\text { (biomassa carbonizada) (China) }\end{array}$ & $\begin{array}{l}\text { Cryptococcus sp., Talaromyces sp., Cladosporium sp., Trichoderma sp., } \\
\text { Penicillium spp. }\end{array}$ \\
\hline SOUZA et al. (2014) & $\begin{array}{l}\text { Solos de sistema de compostagem na fase II } \\
\text { (Brasil) }\end{array}$ & $\begin{array}{l}\text { Scytalidium thermophilum, Thermomyces lanuginosus, Thermomyces } \\
\text { ibadanensis, Penicillium sp. e Aspergillus sp. }\end{array}$ \\
\hline MENG et al. (2013) & $\begin{array}{l}\text { Amostras de solo argila húmica de uma } \\
\text { floresta subtropical montanhosa na } \\
\text { Montanha Lushan (China) }\end{array}$ & Ambispora spp., Hypocrea spp. \\
\hline PEREIRA et al. (2010) & $\begin{array}{l}\text { Amostras de solo de quatro pontos da região } \\
\text { de Borborema - Paraíba (Brasil) }\end{array}$ & Aspergillus flavus, Acremonium spp.; Penicillium spp., Aspergillus niger. \\
\hline $\begin{array}{l}\text { YARWOOD et al. } \\
\text { (2010) }\end{array}$ & $\begin{array}{l}\text { Solos oriundos das duas plantações } \\
\text { experimentais de árvores (Estados Unidos da } \\
\text { América) }\end{array}$ & $\begin{array}{l}\text { Cryptococcus terriocola, } \\
\text { Cryptococcus podzolicus }\end{array}$ \\
\hline
\end{tabular}

Na Tabela 1 são apresentados os resultados extraídos dos estudos incluídos nesta revisão. Os dados referem-se aos microrganismos encontrados, o tipo de amostra analisada e seus receptivos estudos. É válido ressaltar que os resultados descritos se referem as principais espécies/gênero de fungos encontradas, as 
quais apresentaram maior incidência e/ou maior relevância em cada estudo, não sendo as únicas avaliadas. Além disso, alguns estudos analisaram também outras amostras além de solos, e os resultados referentes a essas análises não foram reportados na tabela por não contemplarem de objetivo de estudo do presente trabalho.

As datas de publicações dos artigos selecionados variaram entre os anos de 2010 a 2016, sendo que a maioria ficou entre os anos de 2016 a 2014, podendo caracterizar o tema como atual. Quanto aos tipos de solos, nem todos os artigos analisados continham características do solo em estudo. Porém, foi possível observar uma variação de diferentes locais analisados, variando de solos urbanos a solos de áreas nativas, argilosos, arenosos ou orgânicos. O solo de compostagem mereceu destaque, pois foi material de estudo em três artigos selecionados. Referente aos microrganismos encontrados, a variedade de espécies também se mostrou bem ampla nos diferentes tipos de amostras. No entanto, os gêneros citados com mais frequência nos estudos foram Penicillium spp., seguido de Fusarium spp., Aspergillus spp., Trichoderma spp., e Verticillium spp.

\section{DISCUSSÃO}

Os fungos provenientes do meio ambiente são chamados de contaminantes, vivendo da degradação da matéria-orgânica, caracterizando-se como saprófitos e desempenham um papel importante nos ecossistemas, cumprindo uma série de funções intimamente relacionadas à fixação do carbono em diferentes formas e envolvidas ativamente na decomposição de matéria-orgânica e nos processos de ciclagem de nutrientes (PEREIRA et al., 2010; YU et al., 2013). Além disso, formam importantes associações com plantas vasculares em forma de micorrizas, são úteis e importantes para uso biotecnológico, e também podem ser responsáveis por causar danos às plantas e também saúde do homem, atuando como patógeno oportunista (SOUZA et al., 2014).

Quando habitam o solo, as diferentes comunidades fúngicas podem variar ao longo do gradiente de elevação, em associação com o pH do solo, o teor de água e a disponibilidade de nutrientes, fazendo como que a diversidade dos microrganismos seja grande nesse tipo de habitat (MENG et al., 2013; YU et al., 2013; SARMIENTO et al., 2016). Nesta revisão foi encontrada variedade de espécies de fungos em amostras de solos, porém alguns gêneros como Penicillium spp., Fusarium spp., Aspergillus spp., Trichoderma spp. mereceram destaque por serem citados com mais frequência nos trabalhos desta revisão.

As espécies do gênero Penicillium spp. geralmente são classificadas como contaminantes em todos os tipos de substratos, e demonstram uma ação mais relevante como agentes que produzem micotoxinas em plantas do que como agentes patogênicos em humanos (SARMIENTO et al., 2016). A contaminação deste fungo nas plantações, pode acarretar na deterioração dos alimentos ou grãos colhidos, o que torna um problema pertinente na economia da agricultura. Este fato pode estar mais relacionado com muitas regiões tropicais e subtropicais, pois lá o clima permite a produção agrícola durante o ano todo, e essas mesmas condições, também são propícias ao desenvolvimento de fungos, especialmente, desse gênero (RIBEIRO et al., 2003; MONTEIRO, 2012). 
Contudo, as espécies pertencentes a esse gênero têm sido utilizadas como modelo em muitas pesquisas e têm demonstrado o seu enorme potencial biotecnológico. Algumas espécies podem ser utilizadas como biocontrole, em micoparasitismo, na utilização de seus metabólitos secundários para diversas indústrias, e além disso, são fontes de enzimas de interesse industrial e de novos fármacos para a indústria farmacêutica (MONTEIRO, 2012).

Em relação a presença de Fusarium sp., este é um grande gênero cosmopolita, ou seja, possui uma ampla distribuição na natureza, podendo ser encontrados em praticamente todos os lugares, por isso não é surpreendente encontrá-lo como uma das principais comunidades fúngicas identificadas em diferentes tipos de solos analisados nos trabalhos desta revisão. Muitas espécies deste gênero são agentes patogênicos das plantas e produzem várias toxinas de relevância agrícola. Os genomas das espécies de Fusarium spp. geralmente contêm um número relativamente elevado de genes que codificam a síntese de peptídeos nãotumorais (NRPS), por isso são capazes de produzir uma grande variedade de metabólitos secundários (MA et al., 2013; ESTRADA-MEDINA et al., 2016). E devido a isso, por possuírem grande potencial na produção de metabólitos, espécies do gênero Fusarium spp. têm sido relacionadas com a produção de enzimas e substancias de importância biotecnológica que podem ser utilizadas tanto na medicina como na agricultura (CHAPLA et al., 2013; LUZ et al., 2006). De acordo com Chapla et al. (2013), a Vincristina, um importante anticancerígeno, já foi isolada de cepas de Fusarium oxysporum obtidas da planta Catharanthus roseus, na qual o composto também pode ser encontrado.

Grande maioria das espécies de Fusarium spp. são fungos transmitidos pelo solo e podem permanecer vivos por muito tempo antes de infectar seus hospedeiros (MORETTI, 2009), e quando infectam podem trazer prejuízos, visto que geralmente este fungo apresenta grande resistência a drogas antifúngicas (MA et al., 2013; ESTRADA-MEDINA et al., 2016; SARMIENTO et al., 2016).

As espécies do gênero Aspergillus spp. são de grande interesse por sua capacidade de fermentação e por seu impacto negativo na contaminação de produtos agrícolas, bem como pela sua patogenicidade e toxicidade em mamíferos (MONTEIRO, 2012; SARMIENTO et al., 2016). O gênero Aspergillus sp. é constituído de mais de 200 espécies, e cerca de 20 dessas podem ser patogênicas para o homem e animais. E assim como Fusarium spp., esses fungos são considerados cosmopolitas e extremamente presentes na natureza, sendo encontrados em restos orgânicos, no solo, no ar, em diversos veículos líquidos, sobre a superfície dos seres vivos e etc. (PEREIRA et al., 2010; SARMIENTO et al., 2016).

Por estarem onipresentes no ambiente, tais fungos podem ser veiculados facilmente por correntes áreas, e mesmo que embora grande maioria dos fungos desses gêneros não apresentam uma virulência clássica, podem acabar atuando como patógenos oportunistas, causando infecções (PEREIRA et al., 2010). No estudo de Pereira et al. (2010), o qual teve como objetivos isolar, quantificar e identificar espécies do solo e do ar atmosférico de uma região, Aspergillus flavus foi o fungo detectado com mais frequência nas amostras de solo. E embora seja um fungo geralmente contaminante, de acordo com autor, possui capacidade de ser patogênico em humanos relacionado principalmente a problemas oculares e pulmonares, além de produzir aflatoxinas (PEREIRA et al., 2010). 
Em relação à importância econômica, Aspergillus sp. é um dos gêneros de fungos economicamente mais importantes, muitos isolados são utilizados na produção de diversos produtos, pois possuem a capacidade de secretar enzimas no meio ambiente que auxiliam na degradação de produtos e compostos, sendo amplamente empregados em processos biotecnológicos, devido à produção de enzimas importantes (MONTEIRO, 2012).

Quanto a presença de isolados de Trichoderma spp. nas amostras de solos que estavam envolvidas com processo de compostagem, pode estar relacionada ao fato de que espécies desse gênero são facilmente encontradas em solos com restos de vegetais e outras formas de matéria-orgânica (ETHUR et al., 2008). Algumas linhagens de Trichoderma, quando encontradas em solos rizosféricos podem promover o crescimento vegetal e proteger o sistema radicular da infecção por patógenos, devido a sua versatilidade de ação, como parasitismo, antibiose e competição, além de atuarem como indutores de resistência das plantas contra doenças (ETHUR et al., 2008; MACHADO et al., 2012).

Além da diversidade das comunidades fúngicas observada nas amostras, as concentrações de fungos também variaram em relação aos diferentes tipos e localização dos solos. Solos superficiais apresentaram concentrações e diversidade maior de fungos, quando comparadas com solos mais profundos. Essa diferença de população provavelmente reflete ao fato de que o solo superficial é afetado pelo ar ambiente, e também à temperatura, onde na camada mais externa dos solos, as temperaturas são mais baixas, o que facilita o crescimento de fungos mesófilos, principalmente aqueles dos gêneros Aspergillus sp. e Penicillium sp., os quais crescem bem a temperaturas intermediárias entre 30 e 40ㄷ (SOUZA et al., 2014; HAAS et al., 2016).

De acordo com os estudos desta revisão que analisaram solos oriundos de sistemas compostagem (SOUZA et al., 2014; LANGARICA-FUENTES et al., 2015; HAAS et al., 2016), o aumento da temperatura, principalmente durante a fase II, na qual as temperaturas são mais uniformes em todo o composto, podendo atingir temperaturas tão altas quanto $70 \stackrel{\circ}{ } \mathrm{C}$, contribui claramente para a redução das populações de fungos mesófilos no composto (SOUZA et al., 2014), e favorece o desenvolvimento de fungos termofílicos. No entanto, mesmo assim, o aumento da temperatura durante a compostagem relacionado ao aumento da profundidade do local de amostragem acarreta em uma redução contínua de microrganismos (HAAS et al., 2016). Os fungos termofílicos são de grande interesse para a biotecnologia, pois podem ser úteis na conversão da biomassa, visto que as enzimas produzidas por esses fungos mais estáveis ao calor do que aquelas produzidas por fungos mesofílicos (SOUZA et al., 2014).

Outra condição que pode favorecer o desenvolvimento e sobrevivência de alguns fungos no solo, é a presença da melanina na sua parede celular. A melanina é um biopolímero que protege contra a radiação UV, temperaturas extremas, agentes oxidantes e, além disso, pode conferir virulência ao microrganismo. Portanto, a presença de melanina, que caracteriza esses fungos dematiáceos, dá-lhes maior resistência à radiação ultravioleta, o que lhes permite sobreviver em ambientes inóspitos e/ou onde a radiação solar é alta (GIUSIANO et al., 2002; KEJŽAR et al., 2013; SARMIENTO et al., 2016). E embora não estejam entre os mais frequentes microrganismos citados nos estudos, muitos dos fungos isolados em amostra de solos eram fungos dematiáceos ou pigmentados, como Curvularia spp., Alternaria spp., Cladosporium spp., e 
Phialophora spp. (YU et al., 2013; HU et al., 2014; SARMIENTO et al., 2016).

Além das espécies dematiáceas, no solo também são encontrados os fungos dematófitos geofílicos. No estudo de Sarmiento et al. (2016), o qual analisram amostras de solos de parques de uma cidade na Argentina, afim de pesquisar fungos patogênicos, tanto para humanos quanto para animais, encontraram uma diversidade de espécies de fungos dermatófitos em suas amostras. Em especial Microsporum gypseum, que se caracteriza como um fungo dermatófito geofílico, o qual tem seu habitat natural no solo e é reconhecido como um patógeno humano, que infecta os pacientes após o contato com o solo ou com animais contaminados. Quanto a presença desse tipo de fungo no solo, os autores concluíram que possivelmente, as condições ambientais e a riqueza na queratina do solo dos parques favoreceram a permanência dos propágulos deste fungo, pois é a partir da queratina que estes microrganismos obtêm os nutrientes necessários para sobreviver.

E relação ao clima e sazonalidade, apenas dois artigos analisaram a diferença de crescimento fúngico em diferentes estações. No estudo de Sarmiento et al. (2016), concluíram que a quantidade de fungos filamentosos encontrados foi maior no outono do que na primavera. No trabalho de Yu et al. (2013) foi observado um aumento de espécies nas comunidades fúngicas em espaços abertos durante a estação úmida. No entanto, outro fator como a taxonomia da planta também pode ser considerado um estímulo positivo para a maior diversidade de espécies de fungos, visto que a vegetação acima do solo pode afetar fatores como o carbono orgânico, o pH, a temperatura e umidade da terra, os quais estão diretamente relacionados ao desenvolvimento dos microrganismos (YU et al., 2013). Por exemplo, os fungos crescem melhor em a valores de $\mathrm{pH}$ abaixo de 5, contudo eles são menos sensíveis ao aumento do pH que as bactérias (MELZ et al., 2009).

Portanto, apesar dos estudos selecionados nesta revisão não apresentarem muitas informações em relação à influência do tipo de solo no desenvolvimento da comunidade fúngica, sabe-se que teores de umidade, conforme Moreira et al. (2006), influenciam diretamente no desenvolvimento da população fúngica, nos quais quanto maior a umidade, consequentemente, maiores as populações de fungos. Assim pode-se concluir que climas e ambientes que possuem períodos de chuva mais frequentes, favorecem a presença e o crescimento de fungos geofílicos. O mesmo comprovou-se nos estudos de Melz et al. (2009), o qual analisou propriedades físico-químicas e microbiológicas de diferentes áreas de um parque de uma cidade no estado de Mato Grosso, Brasil, e por meio dos seus resultados concluiu que em períodos chuvosos a diversidade fúngica aumentou nas três áreas analisadas. Na época de seca houve predomínio da população fúngica na área de reserva natural do parque, possivelmente, devido à cobertura vegetal a qual proporcionou as melhores condições para estes microrganismos se desenvolverem (MELZ et al., 2009).

Além disso, sistemas de uso do solo que proporcionam o acúmulo de matéria- orgânica na superfície do solo favorecem o desenvolvimento de microrganismos, dentre eles, os fungos. Solos oriundos de sistemas de compostagem e amostras de áreas agrícolas submetidas a manejo de solo, por proporcionarem um acúmulo maior de matéria-orgânica, tendem a apresentar uma maior riqueza de espécies fúngicas quando comparadas a áreas agrícolas de manejo ou florestas nativas (CARVALHO, 2008). 


\section{CONCLUSÕES}

Diante dos resultados apresentados e discutidos no presente trabalho, foi observada uma grande diversidade de espécies presentes no solo, no entanto, os gêneros citados com mais frequência nos estudos foram Penicillium spp., seguido de Fusarium spp., Aspergillus spp., Trichoderma spp., e Verticillium sp. As amostras de solos analisadas também se mostram bastante diversificadas, variando de solos urbanos a solos de áreas nativas, argilosos, arenosos e/ou orgânicos. Observou-se também que grande parte dos microrganismos citados neste trabalho já são ou podem ser utilizados para fins biotecnológicos, sendo fontes de diversas enzimas e produtores de compostos importantes, como compostos orgânicos, antibióticos e micotoxinas.

Percebeu-se que a influência do tipo de solo nas comunidades fúngicas geofílicas ainda é pouco discutida, porém aspectos generalistas referentes à umidade, à temperatura, à posição e à composição orgânica do solo mostraram-se bastante influenciáveis no desenvolvimento das mesmas, onde solos mais úmidos, superficiais e como maior oferta de material orgânico aumentam a presença e o crescimento de organismos fúngicos.

Além disso, foi possível perceber a importância dos fungos geofílicos no ecossistema e no desenvolvimento de aplicações biotecnológicas. Entre as suas diversas funções, destacam-se a decomposição de resíduos orgânicos e de xenobióticos, o controle biológico, a agregação do solo e a mineralização de nutrientes, e ainda, a construção de relações simbióticas no meio em que se desenvolvem. Assim, percebese a importância de conhecer melhor a diversidade de fungos encontrados em solos, por se tratarem de um amplo reservatório de microrganismos de grande importância ecológica e econômica, os quais são importantes para as interações ambientais e aplicações biotecnológicas.

Contudo, é válido ressaltar, que o presente estudo possui algumas limitações quanto a especificidade dos resultados, visto que pesquisas de dados foi realizada de uma maneira generalizada, na qual foram apresentados somente os principais resultados, não sendo os únicos. Além disso, reforça-se a necessidade de estudos mais aprofundados que examinem mais especificamente o efeito do solo e das variáveis ambientais nas comunidades fúngicas geofílicas.

\section{REFERÊNCIAS}

CAVALCANTI, M. A. Q.; OLIVEIRA, L. G.; FERNANDES, M. J.; LIMA, D. M.. Fungos filamentosos isolados do solo em municípios na região Xingó, Brasil. Acta Botânica Brasileira, v.20, n.4, p.831-837, 2006.

CARVALHO, V. C.. Comunidades de Fungos em Solo do Cerrado sob Vegetação Nativa e sob Cultivo de Soja. Dissertação (Mestrado em Microbiologia Agrícola) Universidade Federal de Lavras, Belo Horizonte, 2008.

CARDOSO, E. J. B. N.; ANDREOTE, F. D.. Microbiologia do solo. 2 ed. Piracicaba: FEALQ, 2016.

CARSON, J. K.; GLEESON, D. B. ; CLIPSON, N.; MURPHY, D. V.. Afforestation alters community structure of soil fungi. Fungal Biology, v.114, p.580-584, 2010. DOI:

\section{https://doi.org/10.1016/j.funbio.2010.04.008}

CHAPLA, V. M.; BIASETTO, C. R.; ARAUJO, A. R.. Fungos Endofíticos: uma fonte inexplorada e sustentável de novos e bioativos produtos naturais. Revista Virtual de Química, v.5, n.3, p.421-437, 2013. DOI: https://doi.org/10.5935/1984$\underline{6835.20130036}$

ESTRADA-MEDINA, H.; CANTO-CANCHÉ, B. B.; SANTOSBRIONES, C. D.; O'CONNOR-SÁNCHEZ, A.. Yucatán in black and red: Linking edaphic analysis and pyrosequencing-based assessment of bacterial and fungal community structures in the two main kinds of soil of Yucatán State. Microbiological Research, v.188-189, p.23-33, 2016. DOI: https://doi.org/10.1016/j.micres.2016.04.007 
ETHUR, L. Z.; BLUME, E.; MUNIZ, M. F. B.; ANTONIOLLI, Z. I.; NICOLINI, C.; MILANESI, P.; FORTES, F. F.. Presença dos gêneros Trichoderma e Fusarium em solo rizosférico e não rizosférico cultivado com tomateiro e pepineiro, em horta e estufa. Ciência Rural, v.38, n.1, p.19-26, 2008. DOI: http://dx.doi.org/10.1590/S0103-84782008000100004

GIUSIANO, G.; PIONTELLI, E.; MANGIATERRA, M. M.; SOSA, M. A.. Distribución altitudinal de hongos queratinófilos, epífitos y endófitos en suelos semiáridos del noroeste argentino (Prov. de Jujuy, $23^{\circ} \mathrm{S}$ y $66^{\circ} \mathrm{O}$ ). Boletín Micológico, v.17, p.51-62, 2002. DOI:

https://doi.org/10.22370/bolmicol.2002.17.0.437

HAAS, D.; LESCH, S.; BUZINA, W.; GALLER, H.; GUTSCHI, A. M.; HABIB, J.; PFEIFER, B.; LUXNER, J.; REINTHALER, F. F.. Culturable fungi in potting soils and compost. Medical Mycology, v.54, n.8, p.825-834, 2016. DOI: https://doi.org/10.1093/mmy/myw047

HU, L.; CAO, L.; ZHANG, R.. Bacterial and fungal taxon changes in soil microbial community composition induced by short-term biochar amendment in red oxidized loam soil. World Journal of Microbiology and Biotechnology, v.30, n.3, p.1085-1092, 2014. DOI: https://doi.org/10.1007/s11274-013-1528-5

KEJŽAR, A.; GOBEC, S.; PLEMENITAS, A.; LENASSI, M. Melanin is crucial for growth of the black yeast Hortaea werneckii in its natural hypersaline environment. Fungal Biology, v.117, n.5, p.368-379, 2013. DOI: https://doi.org/10.1016/j.funbio.2013.03.006

LANGARICA-FUENTES, A.; FOX, G.; ROBSON, G. D.. Metabarcoding analysis of home composts reveals distinctive fungal communities with a high number of unassigned sequences. Microbiology (Reading, England), v.161, n.10, p.1921-1932, 2015. DOI: https://doi.org/10.1099/mic.0.000153

LUZ, J. S.; SILVA, R. L. O.; SILVEIRA, E. B.; CAVALCANTE, U. M. T.. Atividade enzimática de fungos endofíticos e efeito na promoção do crescimento de mudas de maracujazeiroamarelo. Revista Caatinga, v.19, n.2, p.128-134, 2006.

MA, L. J.; GEISER, D. M.; PROCTOR, R. H.; ROONEY, A. P.; O'DONNELL K.; TRAIL, F.; GARDINER, D. M.; MANNERS, J. M.; KAZAN, K.. Fusarium Pathogenomics. Annual Review of Microbiology, v.67, n.1, p.399-416, 2013. DOI: https://doi.org/10.1146/annurev-micro-092412-155650

MACHADO, D. F. M.; PARZIANELLO, F. R.; SILVA, A. C. F.; ANTONIOLLI, Z. I..Trichoderma no Brasil: o fungo e o bioagente. Revista de Ciências Agrárias, v.35, n.1, p.274288, 2012.

MELZ, E. M.; TIAGO, P. V.. Propriedades físico-químicas e microbiológicas do solo de um Parque em Tangará da Serra, MT, uma área de transição entre Amazônia e Cerrado. Acta
Amazonica, v.39, n.4, p.829-834, 2009. DOI:

http://dx.doi.org/10.1590/S0044-59672009000400011

MENG, H.; LI, K.; NIE, M.; WAN, J. R.; QUAN, Z. X.; FANG, C. M.; CHEN, J. K.; GU, J. D.; LI, B.. Responses of bacterial and fungal communities to an elevation gradient in a subtropical montane forest of China. Applied Microbiology and Biotechnology, v.97, n.5, p.2219-2230, 2013. DOI: http://dx.doi.org/10.1007/s00253-012-4063-7

MONTEIRO, M. C. P.. Aspergillus e Penicillium em Solos Preservados do Cerrado. Dissertação (Mestrado em Microbiologia Agrícola) - Universidade Federal de Lavras, Belo Horizonte, 2012.

MOREIRA, F. M. S.; SIQUEIRA, J. O.. Microbiologia e Biotecnologia do Solo. 2 ed. Belo Horizonte: UFLA, 2006.

MORETTI, A.. Taxonomy of Fusarium genus: A continuous fight between lumpers and splitters. Zbornik Matice srpske za prirodne nauke, n.117, p.7-13, 2009. DOI: http://dx.doi.org/10.2298/ZMSPN0917007M

PEREIRA, F. D. O.; LIMA, E. O.; OLIVEIRA, E.; FIGUEIREDO, K. R. L.; BRITO, L. L.; MEIRO, A. S.. Microbiota fúngica do solo e ar atmosférico na região da Borborema, estado da Paraíba, Brasil. Revista brasileira de análises clínicas, v.42, n.2, p.123-126, 2010.

RIBEIRO, S. A. L.; CAVALCANTI, M. A. Q.; FERNANDES, M.J.S.; LIMA, D. M.M.. Fungos filamentosos isolados de produtos derivados do milho comercializados em Recife, Pernambuco. Revista Brasileira de Botânica, v.26, p.223-229, 2003. DOI: http://dx.doi.org/10.1590/S0100-84042003000200010

SARMIENTO, M. M.; MAGIATERRA, M.; BOJANICH, M. V.; BASUALDO, J. A.. Hongos queratinofílicos en suelos de parques de la ciudad de Corrientes, Argentina. Revista Iberoamericana de Micologia, v.33, n.1, p.7-12, 2016. DOI: https://doi.org/10.1016/j.riam.2015.02.004

SOUZA, T. P.; MARQUES, S. C.; SANTOS, D. M. S.; DIAS, E. S. Analysis of thermophilic fungal populations during phase II of composting for the cultivation of Agaricus subrufescens. World Journal of Microbiology and Biotechnology, v.30, n.9, p.2419-2425, 2014. DOI: https://doi.org/10.1007/s11274-014-1667-3

YARWOOD, S. A.; BOTTOMLEY, P. J.; MYROLD, D. D.. Soil Microbial Communities Associated with Douglas-fir and Red Alder Stands at High- and Low-Productivity Forest Sites in Oregon, USA. Microbial Ecology, v.60, n.3, p.606-617, 2010. DOI: https://doi.org/10.1007/s00248-010-9675-9

YU, J.; GRISHKAN, I.; STEINBERGER, Y.. Microfungalcommunity diversity in Zygophyllum dumosum and Hammada scoparia root zones in the northern Negev Desert. Journal of Basic Microbiology, v.53, n.4, p.390-400, 2013. DOI: https://doi.org/10.1002/jobm.201100597

A CBPC - Companhia Brasileira de Produção Científica (CNPJ: 11.221.422/0001-03) detém os direitos materiais desta publicação. Os direitos referem-se à publicação do trabalho em qualquer parte do mundo, incluindo os direitos às renovações, expansões e disseminações da contribuição, bem como outros direitos subsidiários. Todos os trabalhos publicados eletronicamente poderão posteriormente ser publicados em coletâneas impressas sob coordenação da Sustenere Publishing, da Companhia Brasileira de Produção Científica e seus parceiros autorizados. Os (as) autores (as) preservam os direitos autorais, mas não têm permissão para a publicação da contribuição em outro meio, impresso ou digital, em português ou em tradução. 